Article

\title{
Raptor Feeding Characterization and Dynamic System Simulation Applied to Airport Falconry
}

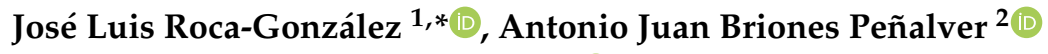 \\ and Francisco Campuzano-Bolarín ${ }^{2}$ (D) \\ 1 Department of Engineering and Applied Technologies, \\ University Centre of Defence at the Spanish Air Force Academy, 30720 Santiago de la Ribera, Spain \\ 2 Department of Business Economics, Universidad Politécnica de Cartagena, 30201 Cartagena, Spain; \\ aj.briones@upct.es (A.J.B.P.); Francisco.campuzano@upct.es (F.C.-B.) \\ * Correspondence: jluis.roca@cud.upct.es
}

Received: 25 September 2020; Accepted: 17 October 2020; Published: 27 October 2020

\begin{abstract}
Airport falconry is a highly effective technique for reducing wildlife strikes on aircraft, which cause great economic losses. As an example, nowadays, wildlife strikes on aircrafts in the air transport industry are estimated to cost between USD 187 and 937 million in the US and USD 1.2 billion worldwide every year. Moreover, the life-threatening danger that wildlife strikes pose to passengers has prompted security stakeholders to develop countermeasures to prevent wildlife impacts near airport transit zones. The experience acquired from international countermeasure analysis reveals that falconry is the most effective technique to create sustainable wildlife exclusion areas. However, its application in airport environments continues to be regarded as an art rather than a technique; falconers modulate raptors' behavior by using a trial-and-error system of controlling their hunger to stimulate the need for prey. This paper focuses on a case study where such a decision-making process was designed as a dynamic system applied to feeding planning for raptors that can be used to set an efficient baseline to optimize raptor responses without damaging existing wildlife. The results were validated by comparing the outputs of the model and the falconer's trial-and-error system, which revealed that the proposed model was $58.15 \%$ more precise.
\end{abstract}

Keywords: wildlife exclusion areas; airport falconry; raptor behavior; dynamic system simulation

\section{Introduction}

The expenses incurred by the US civil air transport industry resulting from wildlife strikes, which cost between USD 187 and 937 million annually over a period of 24 years [1], agree with the figures in international studies. These investigations estimated that the average cost of an occurrence of this type is approximately USD 200,000 [2-4], excluding the effects of fatal accidents, where the cost of lost human life goes beyond the economic impact. Therefore, because wildlife near airports and air transit areas increase the risk of such an event, it is considered a real and serious threat to passengers, aircraft crew, and the air transport industry in general [5]. These circumstances prompted airport managers and security stakeholders [6] to develop procedures to prevent wildlife hazards in airport landscapes. Exclusion areas for wildlife in airport transit zones were created by deploying as many countermeasures as possible.

The results derived from international case studies [7-12] revealed that falconry is the most effective technique to create exclusion areas. However, a deeper analysis of the present falconry methods should be critiqued. Falconry has to be defined as a combination of science and art, rather than merely an art $[13,14]$, as it is usually practiced. Typically, a falconer develops a feeding process for each raptor based on personal experience that simply forces the raptor to hunt when it is released. 
Airport falconry has been estimated to cost approximately USD 130,000 for $24 \mathrm{~h}$ of service and USD 65,000 for $8 \mathrm{~h}$ of service at airports of any size [2]; meanwhile, others have estimated USD 25,000-150,000 [1] or 30,000-50,000 for medium-sized airports [15] for low-operation seasons, nearly USD 950-2900 per week during peak seasons [16] or USD 50,000 per year in other cases [17], and nearly USD 337,500 [18] for bigger airports. Airport safety managers therefore focus on increasing the efficiency of airport falconry [19] to reduce expenses, but also on preserving its performance and capability to create exclusion areas within the airport limits.

Currently, falconry is characterized by a trial-and-error process where falconers identify the "right-hunger" point of each raptor through a self-learning process that finally becomes part of their expertise, which is typically concealed from potential competitors. Consequently, falconry has become an ineffective process that lacks broad ornithological knowledge. Accordingly, falconers need to improve their own learning curve as opposed to having a conceptualization of standard techniques. Advantages could be acquired from other experiences in order to set standards that could enable replication when employed in case studies. This type of knowledge, developed by each falconer, is part of the intellectual capital that has accumulated and derived from the experiences of generations of falconers or records that they may have kept regarding trial-and-error feeding routines that encourage raptors to hunt for prey when they are released. The specific feeding timetables that lead raptors to obtain the best and safest hunting results when released, based on what is known as the right-hunger point, are crucial for understanding the feeding decision process that airport falconers should follow.

The goal of this research was to analyze a case study in which an airport falconer's knowledge is systematically and thoroughly examined in order to model a dynamic system design that could help falconers to perform their job more efficiently. This is made possible by baseline results that can be used to predict the raptor status, which can aid in the decision-making process related to the modulation of raptor feeding to encourage the raptors to maintain the right hunting actions as an example of applying simulations to a practical case study [20].

To achieve this goal, it was necessary to first develop a methodological analysis of a case study based on experiences obtained from the Civil and Military Airport of San Javier (IATA: MJV, OACI: LELC), which is located in the southeast of Spain at latitude 37.7785 and longitude -0.808289 . This airport has two operating runaways: $05 \mathrm{R} / 23 \mathrm{~L}$, which is $2.300 \mathrm{~m}$ long and is used for military purposes only (CASA C-101 and E-26 Tamiz), and $05 \mathrm{~L} / 23 \mathrm{R}$, which is $1.580 \mathrm{~m}$ long and was previously used for civil purposes (Boeing 757 or Airbus A321) until January 2019, when the new International Airport of Murcia was put into service; since then, MJV has been reserved for military use only. Civil transit statistics show that the median value of air operations was 9081 flights in 2018 and nearly 1,095,471 passengers in 2017. Since 2019, the statistical information regarding aircraft operations has not been in the public domain due to its military implications.

Regarding the airport wildlife control service, its assistance made it possible for us to access the daily feeding records of raptors that the airport employed over 10 years (2004-2014). The statistical analysis summarizing several allometric equations that linked the feeding of raptors with the best results when they were released was also accessed. That previous research made it possible to advance to a second stage, where simulation software was utilized to create a dynamic system model that can support future decision-making processes related to airport falconry.

This paper has several sections that explain the following: the typical organization of wildlife control services at airports, the systemic approach analogy, the dynamic model proposal, and the simulations performed with Vensim software to create feeding tables.

\section{Materials and Methods}

\subsection{Wildlife Control Services and Airport Falconry}

The wildlife control service (WCS) employed in airport environments is complex (Figure 1), involving the relational capital of falconers combined with facilities, infrastructures, techniques, 
knowledge, and added value resources in order to create wildlife exclusion areas [21]. Airport falconry, following the instructions of the airport services manual from the International Civil Aviation Organization [22], is an essential part of the task that the WCS performs in combination with other techniques. Airport falconry is considered one of the most effective techniques implemented by the WCS [7]. However, it should be considered as a variation of common falconry techniques in which raptors are typically used to hunt injured or dead prey without intervention. Moreover, airport falconry must preserve wildlife within the bounds of the airport [23]. This prompts falconers to develop tedious training systems for raptors to make them return when a decoy is shown, including the use of tricks that warn the wildlife of the raptor's presence in the exclusion area, such as small bells or warning systems using sound.

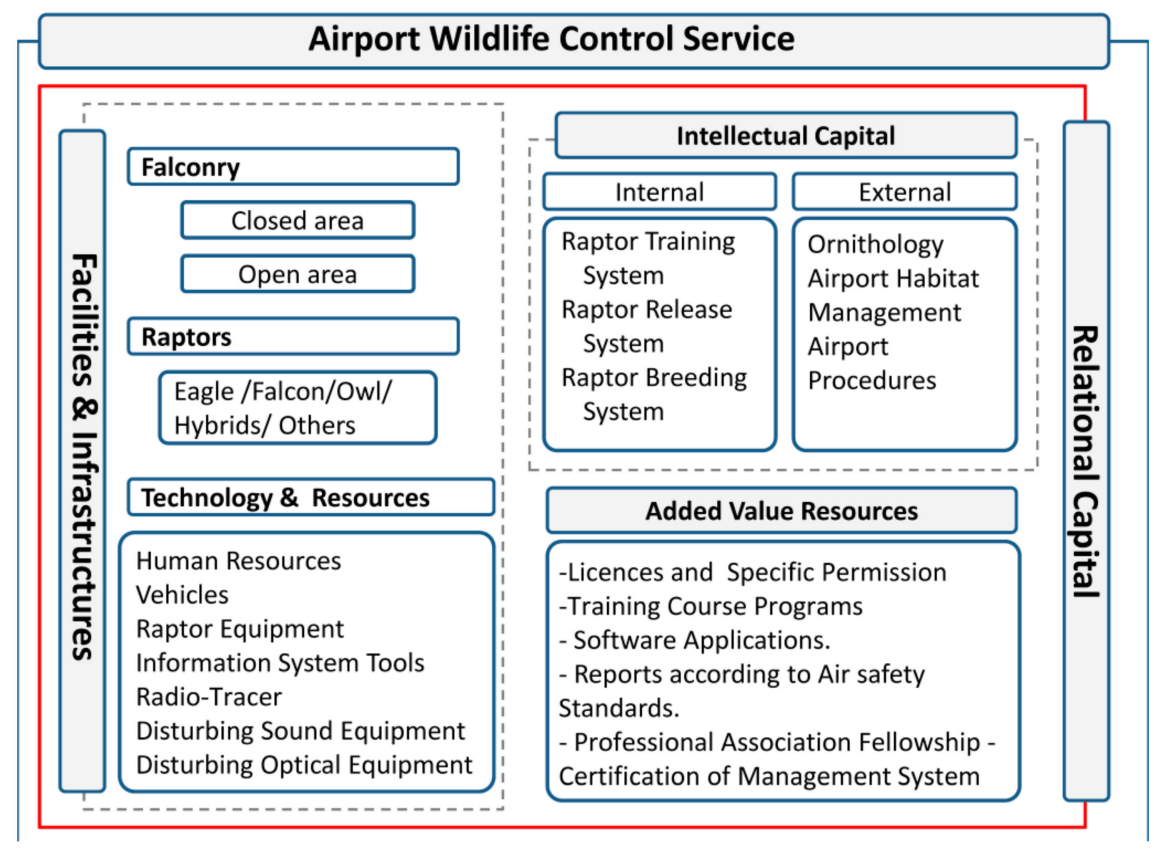

Figure 1. Airport wildlife control service: knowledge management study of airport falconry. Source: [14].

As described above, the aim of airport falconry is to create wildlife exclusion areas rather than to kill prey. Therefore, to understand its implications, it should be redefined as the daily release of trained raptors in airport fields to warn the wildlife in the area of the raptor hunting zones; consequently, this will condition the wildlife to stay away from these zones. Moreover, airport falconry uses modifications of traditional falconry in order to prevent mortality during this activity, thus allowing the coexistence of wildlife and air transport operations.

\subsection{Knowledge and Infrastructure Characterization}

WCS knowledge is characterized by intellectual capital and relational knowledge. Intellectual capital refers to the skill in the use of raptors in two aspects: internal and external. Examples of internal factors include the raptor training program, the release technique, and the feeding process. The external aspects depend on the information gained from each airport, such as knowledge of ornithology and habitats, transit operation ratio, airport design, maintenance weaknesses that offer hiding places for wildlife, and even any possible blockage of water in drainage grates that attract wildlife, among other factors.

The WCS facilities are characterized by the housing provided for birds of prey. This includes all equipment and workspace needed for falconers to care for and feed the raptors. The housing should have enclosed and open areas that can support these activities (Figure 2). Furthermore, the housing must have artificial places that resemble the raptors' natural environment to reduce their stress. 
According to some examples and expert recommendations, the total of both areas should provide a surface area of $3.5 \mathrm{~m}^{2}$ per raptor.

Raptors are defined as a group of birds that have common relatives with genetic and anatomic similarities, such as strong claws, sharp nails, and curved and hooked beaks; these birds usually capture prey with their claws [24]. Raptors can be divided into five taxonomic groups: Cathartidae, Pandionidae, Accipitridae, Sagittarius, and Falconidae for diurnal raptors, and Strigiformes (Strigidae and Tytonidae) for nocturnal raptors [25].

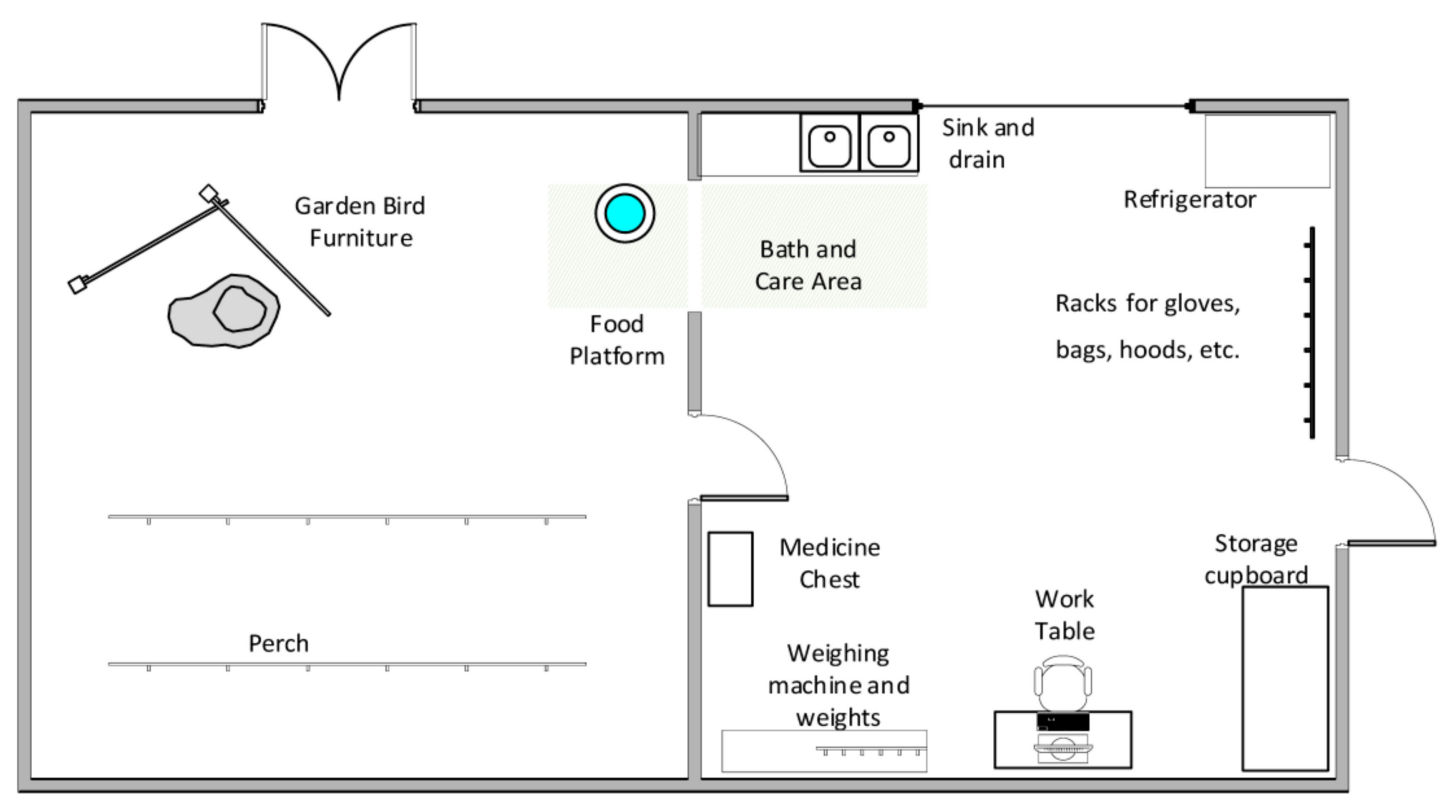

Figure 2. Airport falconry infrastructure: housing for birds of prey [26].

Airport activity has encouraged falconers to simplify the classification into two main groups according to the raptor's hunting strategy (Table 1). Thus, most airport services require some raptors for high-altitude flights and other raptors for low-altitude or hand-to-hand flights. According to this classification, raptors for the high-altitude range take advantage of the potential energy they gain as they fall at a high speed over their prey; this allows them to hunt bigger prey while consuming less energy. Meanwhile, this can increase the potential prey's awareness of the raptors' presence and encourage them to recognize the exclusion area limits. On the other hand, for the low-altitude or hand-to-hand range, raptors use short and fast flights that are considerably closer to the ground than the flights of raptors at a high altitude. Consequently, this disperses the wildlife from covered zones inside the exclusion area.

As there is a clear difference in the hunting strategy between these two types of raptor, it is evident that the energy consumption required for hunting should also be different. In order to apply a systemic approach, the raptors were considered as a "black box", where the main input is feeding and the output is weight plus an evaluation of the hunting flight when the raptor is released. Therefore, the type of raptor for this research did not affect the systemic characterization of the process by defining the specific parameters for each raptor and the generic model. Thereafter, this would allow the analysis of the reliability and accuracy of each model. 
Table 1. Typical raptors used by wildlife control service (WCS).

\begin{tabular}{|c|c|c|c|c|c|}
\hline Raptor & Sex & $\begin{array}{l}\text { Height } \\
\text { (cm) }\end{array}$ & $\begin{array}{l}\text { Wingspan } \\
\text { (cm) }\end{array}$ & $\begin{array}{l}\text { Weight } \\
\text { (g) }\end{array}$ & Main Characteristics \\
\hline \multicolumn{6}{|c|}{ Low-altitude or hand-to-hand flights } \\
\hline Accipiter & $\mathrm{M}$ & $49-56$ & $93-105$ & $510-1170$ & Strong, nervous, with delicate feathers; males are \\
\hline Gentilis & $\mathrm{F}$ & $58-64$ & $108-127$ & $820-1500$ & better for feathered prey and females for hairy prey \\
\hline Accipiter & M & $29-34$ & $58-65$ & $110-200$ & Nervous, aggressive, fast metabolic rate \\
\hline Nisus & $\mathrm{F}$ & $35-41$ & $67-80$ & $185-340$ & Appropriate for preying on other birds \\
\hline Parabuteo & M & $50-60$ & $103-125$ & $450-750$ & Calm, slow metabolic rate \\
\hline Unicinctus & $\mathrm{F}$ & $50-60$ & $103-125$ & $750-1200$ & Ideal for preying on rabbits, hares, squirrels \\
\hline Buteo & M & $45-56$ & $105-135$ & $690-1300$ & Calm, low metabolic rate \\
\hline Jamaicensis & $\mathrm{F}$ & $50-65$ & $105-135$ & $900-1460$ & Ideal for on preying rabbits, hares, squirrels \\
\hline Bubo & M & $60-75$ & $160-188$ & $1580-3000$ & Calm and tough \\
\hline Bubo & $\mathrm{F}$ & $60-75$ & $160-188$ & $1750-4000$ & Appropriate for night hunting \\
\hline Aquila & M & $\sim 80$ & $\sim 200$ & $2650-3800$ & Aggressive, with slow metabolic rate \\
\hline Chrysaëtos & $\mathrm{F}$ & $\sim 80$ & $\sim 200$ & $3600-4600$ & Requires a big area for flying and hunting \\
\hline \multicolumn{6}{|c|}{ High-altitude flights } \\
\hline Peregrinus & $\mathrm{F}$ & $46-51$ & $104-113$ & $850-1300$ & Perfect for hunting feathered prey \\
\hline Falco & M & $\sim 53$ & $110-120$ & $850-1200$ & Strong, good behavior when released hand-to-hand \\
\hline Rusticolus & $\mathrm{F}$ & $\sim 56$ & $120-130$ & $1300-2100$ & Appropriate for hunting feathered prey \\
\hline Falco & M & $\sim 45$ & $100-110$ & 730-990 & High resistance, slow metabolic rate \\
\hline Cherrug & $\mathrm{F}$ & $\sim 55$ & $120-130$ & $970-1300$ & Perfect for any kind of prey \\
\hline Falco & M & $35-40$ & $90-100$ & $500-600$ & Considerably quiet, with high resistance \\
\hline Biarmicus & $\mathrm{F}$ & $45-50$ & $100-110$ & $700-900$ & considerabiy quiet, witn nign resistance \\
\hline Falco & M & $25-30$ & $50-62$ & $125-250$ & Nervous, high metabolic rate \\
\hline Columb. & $\mathrm{F}$ & $25-30$ & $50-62$ & $150-300$ & Limited to hunting feathered prey \\
\hline Falco & M & $32-35$ & $71-80$ & $190-240$ & Calm, with high resistance \\
\hline Tinnun. & $\mathrm{F}$ & $32-35$ & $71-80$ & $220-300$ & High metabolic rate \\
\hline Falco & M & $\sim 25$ & $\sim 55$ & $90-120$ & Quiet, high metabolic rate \\
\hline Sparverius & $\mathrm{F}$ & $\sim 25$ & $\sim 55$ & $90-120$ & Appropriate for hunting small birds. \\
\hline Falco & M & $35-39$ & $78-84$ & $208-305$ & Calm, with high resistance \\
\hline Femoralis & $\mathrm{F}$ & $41-45$ & 93-102 & $310-460$ & Appropriate for bird hunting \\
\hline
\end{tabular}

\subsection{Systemic Characterization}

A systemic characterization of the energy consumption of raptors was first published in 1986, when some authors defined a threshold value for the minimum calories that any raptor needed just to survive [27] and calculated the basal metabolic rate (BMR) as an allometric equation that depends on the raptor weight; see Equation (1). This type of equation was used afterwards [28] to define a specific metabolic rate by multiplying a correction factor by the BMR depending on the type of activity performed by the raptor:

$$
B M R=78 \cdot(\text { Weight })^{0.75}
$$

The systemic approach is then defined by the feeding planning, which is a complex nutritional matter in which several factors can affect the effectiveness, such as digestive efficiency, which depends on the size of the raptor and can increase the food requirement by 10 to $25 \%$; energy-expensive foraging modes, which can increase the food requirement up to $7 \%$ for active hunters; the quality of food, expressed by its nutritional components; and the environmental conditions, which also can affect the nutrition efficiency by 75 to $85 \%$ [29]. As feeding considerations are part of the complex nutritional matter affected by several factors (Figure 3), the decision-making process is simplified with the aid of a closed loop, in which the raptor release results provide the necessary information for the falconer to plan the daily feeding (Figure 4). 


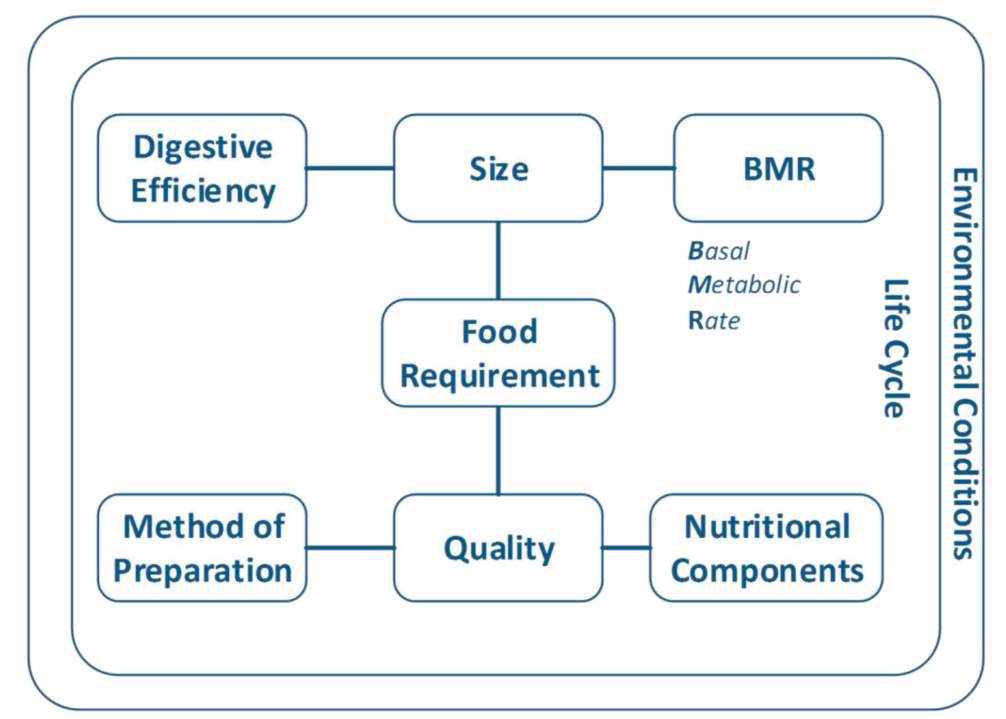

Figure 3. Factors that affect food requirements. Source: [14].

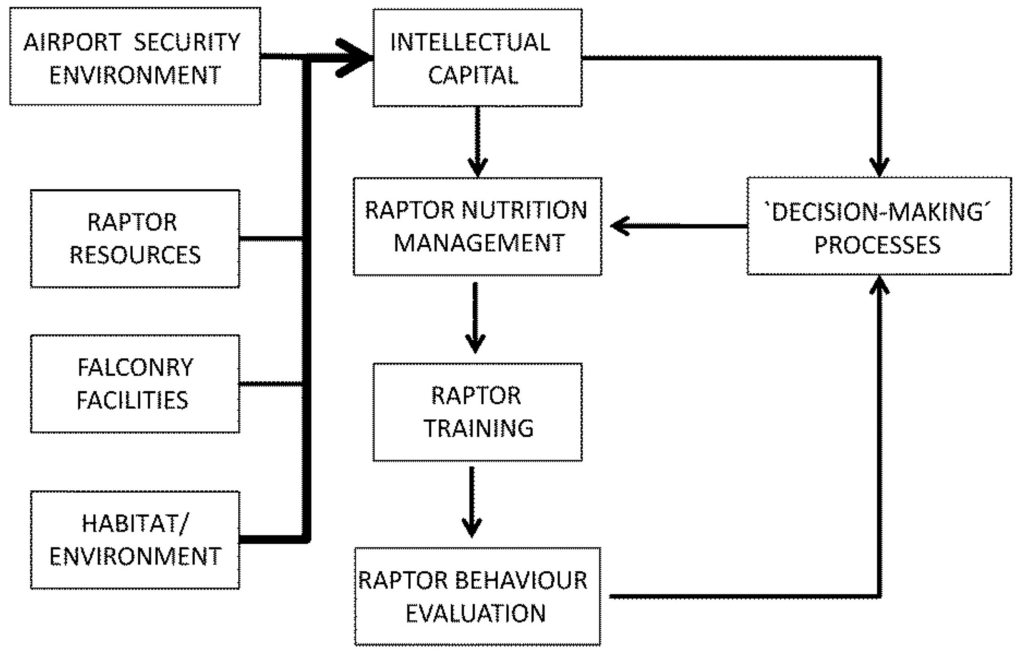

Figure 4. Feeding decision-making process.

The main disadvantage of this closed loop approach is that falconers usually do not have sufficient information to make efficient decisions. This is because such information is limited to the most recent feeding records. Consequently, airport falconers miss other useful information that could be extracted from the statistical analysis of a raptor's past records or from databases pertaining to similar raptor species, which could be helpful in deciding the best feeding plan to reach the right-hunger point at a given time. Based on this concept and a previous case study, results after each raptor's release could be calculated using allometric equations developed for that purpose [21]. The equations were calculated for each season in order to provide the first and third quartile of feeding and establish the upper and lower limits that should lead to the best result when the raptor is released.

\subsection{Expected-Result Equations}

The expected-result equations were derived to provide essential information to falconers in order to plan the feeding of raptors, considering six possible results of their release (see Table 2). For this purpose, in the first stage of the research, eight raptor specimens (three females and five males; see Table 3) and their daily feeding records for a period of 10 years (2004-2014) were analyzed, including their flight evaluation records. Keeping the selected names for the raptors (Niobe, Thirma, Fenix, 
Coz, Titi, Darko, Zeus, and Nico), which expressed the affective bond between raptor and falconer, a database was built, adding numerical codification to represent each raptor's gender and specimen type to aid in reconciling the statistical analysis with the data.

Table 2. Falconer's evaluation range.

\begin{tabular}{|c|c|}
\hline Value & Description \\
\hline 1 & Raptor flies but does not return when called \\
\hline 2 & Bad flight: raptor alights unexpectedly \\
\hline 3 & $\begin{array}{l}\text { Regular flight: raptor's flight height is insufficient; raptor } \\
\text { does not fly over the entire area }\end{array}$ \\
\hline 4 & $\begin{array}{l}\text { Good flight: raptor will reach the expected height but will } \\
\text { not fly over the entire area }\end{array}$ \\
\hline 5 & Very good: raptor flies over the entire area but returns late \\
\hline 6 & $\begin{array}{l}\text { Excellent: raptor's flight height is sufficient; raptor succeeds } \\
\text { at hunting and returns when summoned }\end{array}$ \\
\hline
\end{tabular}

The statistical analysis of the records allowed the derivation of equations that could predict the expected result of a raptor's release in relation to the feeding factor, which was defined as the ratio of supplied calories to the raptor's basal metabolic rate. The equations were calculated following an exponential structure (see Equation (2)) according to the acceptance criterion of the highest value of the square of the Pearson product-moment correlation coefficient, $R^{2}$.

$$
E R_{Q i}={ }^{(a+b \cdot F F)}
$$

Here, $E R_{Q i}$ represents the value of the expected result of a raptor release according to the limit value defined by quartile $i(Q i)$ of feeding factors that corresponded with this result, and $a$ is an independent term and $b$ the factor that modulates the feeding factor, $F F$, defined as the coefficient between the calories supplied by the falconer and the basal metabolic rate of the raptor; see Equation (1).

These equations were also used to plot the curves marking out the area for the first, second, and third quartiles, where the feeding factor may generate the best expected result (ER) for the raptor $(E R=6)$. The expected-result equations for each raptor are listed in the corresponding tables as well as for two generic models, considering the gender, where equations for female and male raptors were created by a new regression of the expected results for each group (see Tables 3 and 4).

Table 3. Parameters of Equation (2) for each raptor analyzed.

\begin{tabular}{cccccccccc}
\hline \multirow{2}{*}{ Raptor } & \multicolumn{3}{c}{ ERQ3 } & \multicolumn{3}{c}{ ERMed } & \multicolumn{3}{c}{ ERQ1 } \\
\cline { 2 - 9 } & $\mathbf{a}$ & $\mathbf{b}$ & $\mathbf{R}^{\mathbf{2}}$ & $\mathbf{a}$ & $\mathbf{b}$ & $\mathbf{R}^{\mathbf{2}}$ & $\mathbf{a}$ & $\mathbf{b}$ & $\mathbf{R}^{\mathbf{2}}$ \\
\hline \multicolumn{8}{c}{ \#01HPGH: Female specimen of Falco Rusticolus $\times$ Peregrinus (Niobe) } \\
\hline Winter & -2.02 & 4.89 & 0.98 & -2.32 & 5.62 & 0.96 & -2.47 & 5.97 & 0.95 \\
Spring & -1.1 & 2.64 & 0.92 & -1.74 & 3.74 & 0.95 & -3.51 & 6.94 & 0.92 \\
Summer & -0.67 & 1.71 & 0.98 & -0.74 & 2.31 & 0.94 & -0.92 & 2.75 & 0.96 \\
Autumn & -1.23 & 2.84 & 0.93 & -1.17 & 3.02 & 0.98 & -0.84 & 2.74 & 0.99 \\
\hline & $\# 02 H S G H:$ Female specimen of Falco Cherrug $\times$ Rusticolus (Thirma) \\
\hline Winter & 4.12 & -3.51 & 0.99 & 3.47 & -3.19 & 0.92 & 1.11 & -1.09 & 0.91 \\
Spring & -0.76 & 1.75 & 0.96 & -0.06 & 1.41 & 0.97 & -0.36 & 2.15 & 0.94 \\
Summer & -2 & 2.84 & 0.93 & -1.6 & 3.26 & 0.92 & -1.48 & 4.16 & 0.95 \\
Autumn & -0.85 & 1.82 & 0.99 & -0.57 & 1.81 & 0.91 & -0.47 & 1.93 & 0.91 \\
\hline
\end{tabular}


Table 3. Cont

\begin{tabular}{|c|c|c|c|c|c|c|c|c|c|}
\hline \multirow{2}{*}{ Raptor } & \multicolumn{3}{|c|}{ ERQ3 } & \multicolumn{3}{|c|}{ ERMed } & \multicolumn{3}{|c|}{ ERQ1 } \\
\hline & $\mathbf{a}$ & $\mathbf{b}$ & $\mathbf{R}^{2}$ & $\mathbf{a}$ & b & $\mathbf{R}^{2}$ & $\mathbf{a}$ & b & $\mathbf{R}^{2}$ \\
\hline \multicolumn{10}{|c|}{ \#03HPGM: Male specimen of Falco Rusticolus × Peregrinus (Fenix) } \\
\hline Winter & 10.25 & -4.61 & 0.99 & 25.77 & 16.89 & 0.98 & 11.17 & -7.82 & 0.99 \\
\hline Spring & 4.16 & -1.63 & 0.91 & 3.58 & -1.62 & 0.97 & 2.96 & -1.29 & 0.92 \\
\hline Summer & 3.62 & -1.57 & 0.98 & 2.88 & -1.23 & 0.95 & 2.72 & -1.29 & 0.91 \\
\hline Autumn & -1.66 & 2.01 & 0.92 & -3.21 & 3.82 & 0.98 & -5.92 & 6.95 & 0.98 \\
\hline \multicolumn{10}{|c|}{ \#04HPGM: Male specimen of Falco Rusticolus × Peregrinus (Coz) } \\
\hline Winter & -4.05 & 2.86 & 0.99 & -5.21 & 3.85 & 0.98 & -5.39 & 4.96 & 0.93 \\
\hline Spring & 9.18 & -5.72 & 0.98 & 9.41 & -6.62 & 0.96 & 10.99 & -8.4 & 0.94 \\
\hline Summer & -3.92 & 4.32 & 0.90 & -5.96 & 6.31 & 0.92 & 5.80 & -5.98 & 0.94 \\
\hline Autumn & -3.58 & 3.18 & 0.99 & -7.18 & 5.86 & 0.97 & -4.67 & 6.94 & 0.94 \\
\hline \multicolumn{10}{|c|}{ \#05HPH: Female specimen of Falco Peregrinus (Titi) } \\
\hline Winter & 2.29 & -1 & 0.99 & 2.34 & -1.34 & 0.92 & 2.63 & -2.07 & 0.91 \\
\hline Spring & 7.82 & -4.78 & 0.99 & 8.81 & -6.14 & 0.95 & 4.51 & -3.67 & 0.96 \\
\hline Summer & 2.53 & -1.25 & 0.92 & 2.58 & -1.60 & 0.94 & 2.75 & -2.06 & 0.94 \\
\hline Autumn & 2.31 & -0.97 & 0.97 & 2.45 & -1.28 & 0.94 & 2.30 & -1.50 & 0.94 \\
\hline \multicolumn{10}{|c|}{ \#06HPGM: Male specimen of Falco Rusticolus $\times$ Peregrinus (Darko) } \\
\hline Winter & -0.86 & 1.14 & 0.90 & -1.13 & 1.37 & 0.94 & -12.82 & 10.44 & 0.97 \\
\hline Spring & -3.59 & 2.73 & 0.93 & -7.3 & 6.00 & 0.97 & -3.36 & 2.73 & 0.93 \\
\hline Summer & -6.08 & 4.23 & 0.98 & -4.34 & 3.58 & 0.92 & -2.32 & 2.52 & 0.98 \\
\hline Autumn & -6.67 & 5.97 & 0.99 & -5.79 & 5.44 & 0.94 & -10.20 & 9.94 & 0.93 \\
\hline \multicolumn{10}{|c|}{ \#07HPGM: Male specimen of Falco Rusticolus × Peregrinus (Zeus) } \\
\hline Winter & -2.89 & 2.75 & 0.99 & -4.06 & 3.70 & 0.91 & -9.84 & 8.15 & 0.97 \\
\hline Spring & 5.86 & -3.46 & 0.93 & 5.81 & -3.52 & 0.99 & 5.47 & -3.41 & 0.90 \\
\hline Summer & 4.44 & -2.23 & 0.99 & 4.43 & -2.47 & 0.96 & 4.31 & -2.65 & 0.97 \\
\hline Autumn & 4.19 & -1.83 & 0.96 & 6.21 & -3.75 & 0.99 & 8.12 & -5.81 & 0.94 \\
\hline \multicolumn{10}{|c|}{ \#08HGSM: Male specimen of Falco Cherrug $\times$ Rusticolus (Nico) } \\
\hline Winter & -3.76 & 2.84 & 0.95 & -6.23 & 4.74 & 0.97 & -9.33 & 7.18 & 0.99 \\
\hline Spring & 2.90 & -3.03 & 0.97 & 3.28 & -1.38 & 0.92 & 4.0 & -1.98 & 0.96 \\
\hline Summer & 2.19 & -0.62 & 0.92 & 2.13 & -0.61 & 0.93 & 2.09 & -0.69 & 0.99 \\
\hline Autumn & -4.44 & 6.46 & 0.91 & -7.50 & 5.80 & 0.95 & -15.76 & 12.08 & 0.98 \\
\hline
\end{tabular}

Source: [14].

Table 4. Parameters of Equation (2) for male/female classification of raptors.

\begin{tabular}{lccccccccc}
\hline \multirow{2}{*}{ Raptor } & \multicolumn{3}{c}{ ERQ3 } & \multicolumn{3}{c}{ ERMed } & \multicolumn{3}{c}{ ERQ1 } \\
\cline { 2 - 9 } & $\mathbf{a}$ & $\mathbf{b}$ & $\mathbf{R}^{\mathbf{2}}$ & $\mathbf{a}$ & $\mathbf{b}$ & $\mathbf{R}^{\mathbf{2}}$ & $\mathbf{a}$ & $\mathbf{b}$ & $\mathbf{R}^{\mathbf{2}}$ \\
\hline \multicolumn{6}{c}{ Generic modeling prediction of expected results for female raptors } \\
\hline Winter & 3.59 & -2.77 & 0.99 & 3.68 & -3.39 & 0.97 & 4.23 & -4.95 & 0.99 \\
Spring & -3.4 & 1.19 & 0.99 & -2.37 & 3.67 & 0.99 & -5.62 & 8.89 & 0.99 \\
Summer & -22.6 & 21.74 & 0.99 & -21.3 & 26.45 & 0.99 & -17.04 & 25.25 & 0.99 \\
Autumn & 24.92 & -22.7 & 0.99 & -18.1 & 21.45 & 0.95 & -9.76 & 14.03 & 0.99 \\
\hline
\end{tabular}


Table 4. Cont.

\begin{tabular}{lccccccccc}
\hline \multirow{2}{*}{ Raptor } & \multicolumn{3}{c}{ ERQ3 } & \multicolumn{3}{c}{ ERMed } & \multicolumn{3}{c}{ ERQ1 } \\
\cline { 2 - 9 } & $\mathbf{a}$ & $\mathbf{b}$ & $\mathbf{R}^{\mathbf{2}}$ & $\mathbf{a}$ & $\mathbf{b}$ & $\mathbf{R}^{\mathbf{2}}$ & $\mathbf{a}$ & $\mathbf{b}$ & $\mathbf{R}^{\mathbf{2}}$ \\
\hline \multicolumn{4}{c}{ Generic modeling prediction of expected results for male raptors } \\
\hline Winter & -3.92 & 2.91 & 0.99 & -4.31 & 3.5 & 0.97 & -13.58 & 10.93 & 0.99 \\
Spring & 5.92 & -3.0 & 0.99 & 5.5 & -3.1 & 0.92 & 4.98 & -2.93 & 0.99 \\
Summer & 4.59 & -2.62 & 0.99 & 4.07 & -2.1 & 0.99 & 3.72 & -2.14 & 0.99 \\
Autumn & -9.18 & 6.99 & 0.91 & -10.75 & 9.58 & 0.95 & 51.14 & -41.6 & 0.98 \\
\hline
\end{tabular}

Source: [14].

\section{Proposed Dynamic System}

The nutritional balance required to lead raptors to reach the right-hunger point can be understood as a dynamical system. Falconers adjust the food input to control the raptors' weight to lead them to right-hunger status. It is analogous to the process of filling a water tank (Figure 5) with two drainage lines at the bottom: one line is for calories that satisfy the energy requirement to survive and perform daily activities, and the other for calories that are used to increase the raptor's weight. Controlling the water tap represents feeding the raptor, and the tank level represents the energy modulated by the raptor that will be used to satisfy the basal metabolic rate plus the exercise energy requirements, transforming excess energy into fat, which in turn increases the raptor's weight.

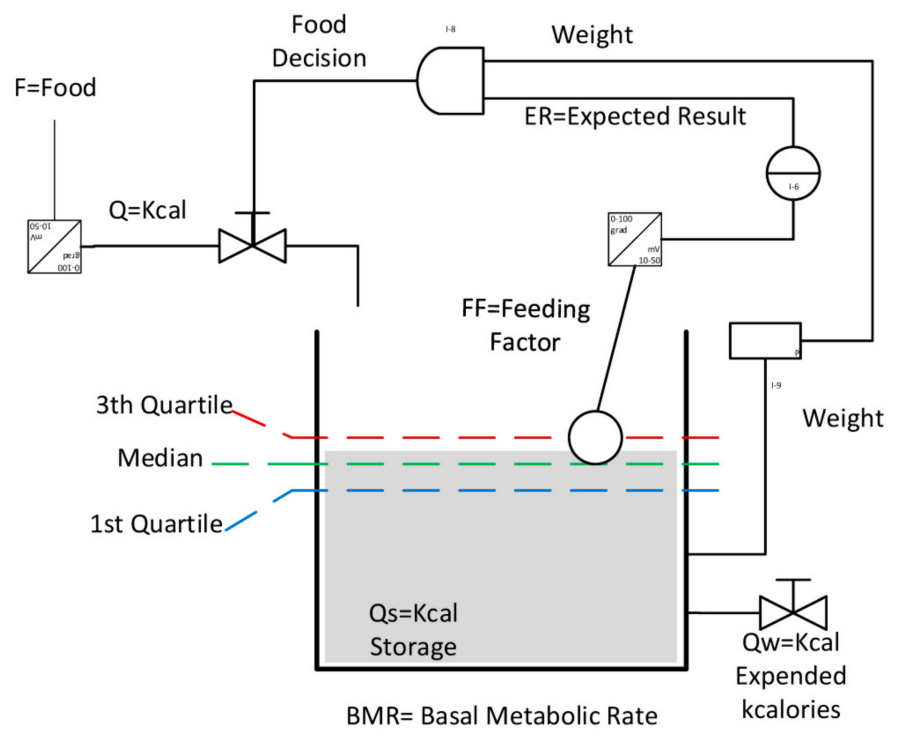

Figure 5. Dynamic system: water filling tank analogy.

Falconers, acting as decision-makers regarding the amount of food to be assigned, have to know the daily weight of each raptor in order to calculate the basal metabolic rate and contrast it with the input of calories. This ratio between caloric input and required minimum is commonly called the feeding factor. Hence, a ratio less than 1 means that the falconer decided to reduce the raptor's weight, and a ratio greater than 1 means that the falconer opted to increase it. The basal metabolic rate is calculated by an allometric equation that depends on weight, whereas the caloric input is obtained by a food subsystem that determines the equivalent calorie counts of food items. The expected results can be quickly obtained by using an equation that depends on the feeding factor. 


\section{Variable Characterization}

- Food: This is an independent and qualitative variable defined by the nutritional items the falconer supplies to the raptor. Food items are usually day-old chicks or chicken wings, thigh, or breast portions. Professional falconers source them from food raptor farms, which allow the tracking of nutritional information for each food item.

- Q: This parameter, which is dependent on the food variable, is a quantitative and continuous variable that represents the calories supplied by each food input. The food transformation system transduces the food variable into a numerical value that represents the energy (calories) supplied to the raptor (Table 5).

- Weight: Initially, this is an independent variable. In the model design, it becomes a dependent variable for stored and consumed energy; it is a quantitative and continuous variable that represents the weight of a raptor expressed in $\mathrm{kg}$.

- FF: This is a dependent variable that represents the feeding factor by means of the ratio of $Q$ to $\mathrm{BMR}: \mathrm{FF}=\mathrm{Q} / \mathrm{BMR}$; it is a quantitative and continuous variable.

- Season: This variable is dependent on time. It is a qualitative and discrete variable that represents the seasonal effects when modelling raptor behavior and nutritional needs.

- ER: This variable, which is dependent on FF and season, is a quantitative and discrete variable (between 1 and 6) that evaluates the release of the raptor, with 1 representing the worst possible result and 6 the best possible result (Table 2).

- BMR: This variable, which is dependent on weight, is a quantitative and continuous variable. The basal metabolic rate expresses the minimum number of calories that the raptor requires to survive (assuming it remains in a resting state), (see Equation (1)) [27].

Table 5. Food-calorie conversion.

\begin{tabular}{cc}
\hline Food Description & kcal/Unit \\
\hline Day-old chicks & 39.6 \\
Chicken wing portion & 57.96 \\
Chicken breast portion & 38.22 \\
\hline
\end{tabular}

Extracted from nutritional descriptions of Labdial food supplier.

\subsection{Simulation Software Implementation}

Industrial-strength simulations can help improve an airport falconer's decision-making capacity by implementing a dynamic system that can be used to obtain a feeding baseline plan associated with the best expected result. In order to set up this type of simulation, Vensim is suitable software that allows the creation of a dynamic model to run the required iterations for the final result. This software offers a simple interface to design a high-quality model, data connections, flexible distribution, and advanced algorithms.

The model design is similar to the conventional problem of water tank filling (Figure 6), in which there is an input of calories to feed the raptor and a minimum caloric energy required for the raptor to survive, plus additional energy for the hunting flight. The tank-level objective is defined by the feeding factor that leads to the best result, that is, the limits defined by the first and third percentiles of the feeding factor that were previously obtained by the expected model for each raptor. 


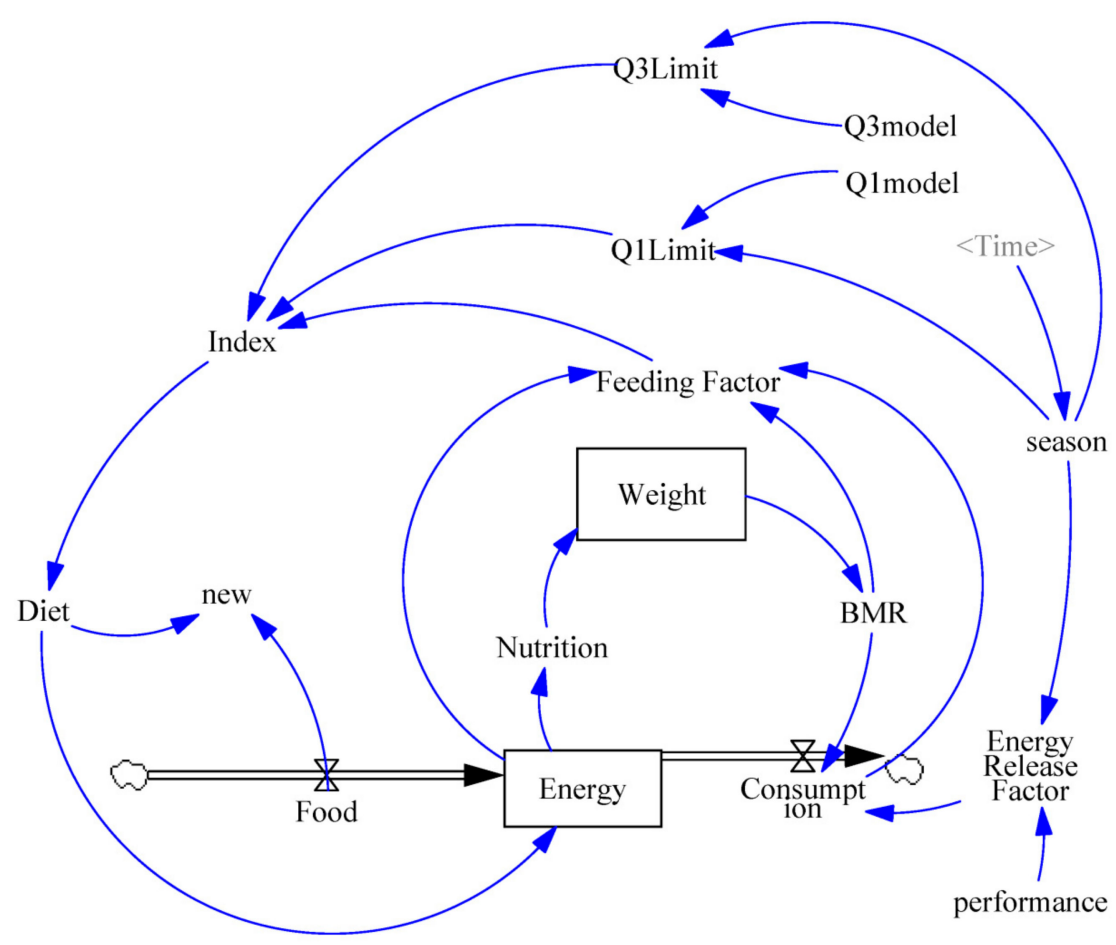

Figure 6. Proposed dynamic system designed with Vensim software.

The stored energy can be converted into a weight-change ratio by means of a statistical analysis performed in previous research showing that for each kilocalorie supplied a day before weighing, it can be assumed that the weight will increase by $0.1 \mathrm{~g}$. This conversion ratio is the reference value considered in this research, where several assumptions were made, and it may not be correct to extrapolate them to other case studies with different boundary conditions. The seasonal component affects not only the expected result, but also the energy consumption, because of the raptor's daily activities. This can be expressed in terms of BMR: 0.2 times the BMR for winter, 0.25 for spring, 0.3 for summer, and 0.25 for autumn, as reported by international studies [28,29].

\subsection{Vensim Variables}

Vensim software uses different types of variables, such as level, auxiliary, data, constant, lookups, and arrows, including an equation editor, in order to display the internal relationships between them. In this case, the water tank analogy is an aid to understanding how raptor modeling uses level variables such as energy and weight as storage capacity that represents a level for accumulating positive or negative inputs, which can increase or decrease their initial values.

Auxiliary variables perform an important function; sometimes the main purpose is to provide easy access to an intermediate operation value in order to clearly plot its effects on the process. For example, the New variable is used to add the value of the Diet variable to the baseline food plan that corresponds to the Food variable.

The rest of the variables are summarized in Table 6 . These variables play a part in the three main loops that combine them in groups of four, six, and seven steps per loop. The first loop depends on the variables Weight, Consumption, Energy, and Nutrition; the second loop depends on Weight, BMR, Feeding Factor, Index, Diet, Energy, and Nutrition; and the third loop depends on Weight, BMR, Consumption, Feeding Factor, Index, Diet, Energy, and Nutrition. Feeding Factor is therefore influenced by Energy, BMR, and Consumption; Diet is influenced by Index, which depends on Feeding Factor, Q3Limit, and Q1Limit; and Consumption is defined by BMR and Energy Release Factor, all of which are represented more clearly because of the causal tree that characterizes the Vensim model (Figure 7). 


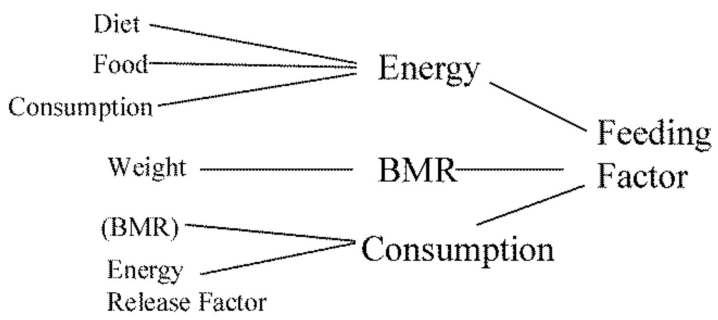

(a)

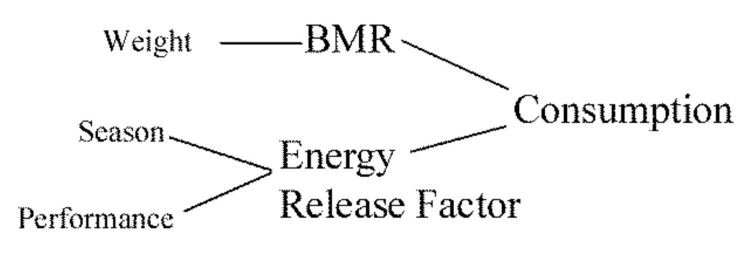

(b)

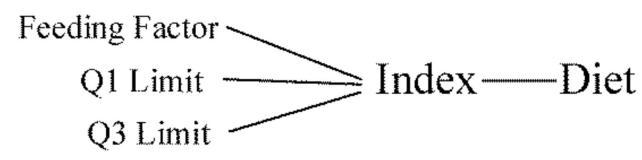

(c)

Figure 7. Causal trees for most relevant variables: (a) feeding factor, (b) diet, and (c) consumption.

Table 6. Variables used in Vensim.

\begin{tabular}{|c|c|c|}
\hline Variable & Description & Unit \\
\hline BMR & $\begin{array}{l}\text { Auxiliary variable to express basal metabolic rate. } \\
<<<\text { BMR }=78 \times(\text { Weight })^{\wedge} 0.75>>\end{array}$ & kcal \\
\hline Diet & $\begin{array}{l}\text { Auxiliary variable that represents nutritional } \\
\text { variation. This variation on the planned standard } \\
\text { food depends on the Index variable. }<<\text { Diet }=\text { IF } \\
\text { THEN ELSE(Index }<0, \alpha, 0)+ \text { IF THEN ELSE(Index }= \\
0.5, \beta, 0)++ \text { IF THEN ELSE(Index }=1, \gamma, 0)>>\text {, where } \alpha \text {, } \\
\beta \text {, and } \gamma \text { are calories (kcal) of standard portions of } \\
\text { food most commonly used to increase or decrease } \\
\text { the diet (Table } 7 \text { ). }\end{array}$ & kcal \\
\hline Energy & $\begin{array}{c}\text { Level of stored energy. }<<\text { Energy }=\text { INTEG }(+ \text { Food }+ \\
\text { Diet }- \text { Consumption, } 0)>>\end{array}$ & kcal \\
\hline Food & $\begin{array}{c}\text { Auxiliary variable that expresses standard feeding } \\
\text { plan (in kcal), estimated by means of case study } \\
\text { analysis; most commonly } 150 \mathrm{kcal} .<<\text { Food }= \\
\operatorname{PULSE}(0,366) \times 150>>\end{array}$ & kcal \\
\hline Index & $\begin{array}{l}\text { Auxiliary variable indicating that if feeding factor is } \\
\text { over Q3 limits, its value is }-1 \text {; if between Q3 and Q1 } \\
\text { limits, its value is 0.5; if under Q1 limits, its value is } \\
\text { +1. << Index = IF THEN ELSE(Feeding Factor }< \\
\text { Q3Limit:AND:Feeding Factor }>\text { Q1Limit,0.5, } 0 \text { )++IF } \\
\text { THEN (Feeding Factor }>\text { Q3Limit, }-1,0)+ \text { IF THEN } \\
\text { ELSE(Feeding Factor }<\text { Q1Limit,1,0) >> }\end{array}$ & Dml \\
\hline New & $\begin{array}{c}\text { Auxiliary variable for new feeding input. }<<\mathrm{New}= \\
\text { Diet }+ \text { Food }>>\end{array}$ & kcal \\
\hline Nutrition & $\begin{array}{c}\text { Auxiliary variable that represents weight variation } \\
\text { caused by energy balance between calorie supply } \\
\text { and energy consumption. }<<\text { Nutrition = Energy } \times \\
0.0001>>\end{array}$ & $\mathrm{kg}$ \\
\hline
\end{tabular}


Table 6. Cont.

\begin{tabular}{|c|c|c|}
\hline Variable & Description & Unit \\
\hline Performance & $\begin{array}{l}\text { Lookup variable that represents seasonal effects on } \\
\text { daily activity. }<<\text { Performance }([(1,0)- \\
(4,4)],(1,0.2),(2,0.25),(3,0.3),(4,0.25))>>\end{array}$ & Dml \\
\hline Q3Limit & $\begin{array}{l}\text { Auxiliary variable that represents upper limit of } \\
\text { feeding factor (third quartile) that can lead raptor to } \\
\text { a successful flight. }<<\text { Q3Limit }=\text { Q3model(season) }>>\end{array}$ & Dml \\
\hline Q1Limit & $\begin{array}{l}\text { Auxiliary variable that represents lower limit of } \\
\text { feeding factor (first quartile) that can lead raptor to } \\
\text { a successful flight. }<<\text { Q1Limit }=\text { Q1model(season) }>>\end{array}$ & Dml \\
\hline Q3model & $\begin{array}{l}\text { Lookup variable that contains Q3 limits for different } \\
\text { raptor models. Models } 01-08 \text { correspond to species } \\
\text { and gender, models } 09 \text { and } 10 \text { are for female } \\
\text { and male median values, respectively. }<<\mathrm{Q} 3 \text { model(; } \\
\text { GET XLS LOOKUPS('1.xls', 'Q3', 'A', 'K1'))>> }\end{array}$ & Dml \\
\hline Q1model & $\begin{array}{l}\text { Lookup variable that contains all Q1 limits for } \\
\text { different raptor models. Models } 01-08 \text { correspond to } \\
\text { species and gender, models } 09 \text { and } 10 \text { are for female } \\
\text { and male median values, respectively. } \\
<<\text { Q1model(GET XLS LOOKUPS('1.xls', 'Q1' ' 'A', } \\
\text { 'K1'))>> }\end{array}$ & Dml \\
\hline Season & $\begin{array}{c}\text { Auxiliary variable: } 1 \text { for winter, } 2 \text { for spring, } 3 \text { for } \\
\text { summer, } 4 \text { for autumn. }<<\text { season }=\text { IF THEN ELSE } \\
\text { (Time }<=90,1,0)+ \text { IF THEN ELSE (Time }> \\
\text { 90:AND:Time }<=180,2,0)+ \text { IF THEN ELSE(Time }> \\
\text { 180:AND: Time }<=270,3,0)+ \text { IF THEN ELSE(Time }> \\
270,4,0)>>>\end{array}$ & Dml \\
\hline TIME ST & $\begin{array}{l}\text { Shadow variable used to set timing. }<<\text { TIME STEP }= \\
\qquad 1>>\end{array}$ & Day \\
\hline Consumption & $\begin{array}{l}\text { Auxiliary variable for total energy consumed, defined } \\
\text { by BMR and energy needed to accomplish raptor's } \\
\text { activity. }<<(\text { Energy release factor } \times \text { BMR })+\text { BMR }>>\end{array}$ & kcal \\
\hline Weight & $\begin{array}{c}\text { Level variable with an initial value introduced for } \\
\text { each simulation; e.g., for a simulation of a young } \\
\text { raptor, the initial weight is } 0.8 \mathrm{~kg} .<<\text { Weight }= \\
\text { INTEG (Nutrition,0.8) }>>\end{array}$ & $\mathrm{kg}$ \\
\hline $\begin{array}{l}\text { Release Energy } \\
\quad \text { Factor }\end{array}$ & $\begin{array}{l}\text { Auxiliary variable that is a factor to be multiplied by } \\
\text { BMR and added to Consumption. Represents energy } \\
\text { that will be consumed because of raptor activity. } \\
<<\text { Release Energy Factor = Performance(season) }>>\end{array}$ & Dml \\
\hline
\end{tabular}

Dml, dimensionless.

Table 7. Variation parameters (in kcal) of standard portions of food for each model.

\begin{tabular}{ccccccccccc}
\hline Model: & $\mathbf{0 1}$ & $\mathbf{0 2}$ & $\mathbf{0 3}$ & $\mathbf{0 4}$ & $\mathbf{0 5}$ & $\mathbf{0 6}$ & $\mathbf{0 7}$ & $\mathbf{0 8}$ & Female Male \\
\hline$\alpha$ & -90 & -90 & -90 & -90 & -90 & -90 & -90 & -90 & -90 & -50 \\
$\beta$ & -20 & -20 & -20 & -20 & -20 & -40 & -20 & -20 & -20 & 10 \\
$\gamma$ & 30 & 30 & 30 & 30 & 80 & 10 & 30 & 30 & 30 & 50 \\
Food & 150 & 150 & 100 & 100 & 150 & 100 & 100 & 100 & 170 & 100 \\
\hline
\end{tabular}

\subsection{Vensim Simulations}

Simulations were performed for each model, that is, for each raptor selected, including all the years of their existing records in the database. As the model is limited to a step time of one year, the simulations were repeated for each year using the actual value recorded at the beginning of the year as the initial weight. 
Finally, a new database was obtained for each raptor (models 01-08). In order to test the Vensim model's reliability (such as in the other examples), hindcasting was performed by checking whether the model output corresponded to the forecasted values, and whether validation data corresponded to observations [30]. This made it easy to compare several models by examining the mean square error (see Equation (3)) or the symmetric mean absolute percentage error (see Equation (4)) as a modification of this error when the divisor is half the sum of the actual and forecast values [31].

Thus, for each raptor, three models were compared with the developed model: the generic model that depends on the raptor's gender, the falconer behavior that modulates the feeding factor, and the actual feeding plan designed by the falconer. The validation data represent the third percentile value of the feeding factor for each season that leads the raptor to a successful flight when released. The equations used are as follows:

$$
M S E=\frac{1}{n} \sum_{i=1}^{n}\left(Y_{i}-\hat{Y}_{i}\right)^{2}
$$

where $\hat{Y}_{i}$ is a vector of n-predictions and $Y_{i}$ is the vector used as a reference; and

$$
S M A P E=\frac{1}{n} \sum_{t=1}^{n}\left(\frac{\left|F_{t}-A_{t}\right|}{\frac{F_{t}+A_{t}}{2}}\right)
$$

where $F_{t}$ is the forecast value obtained with Vensim and $A_{t}$ is the value used as a reference.

In both cases the reference value corresponded with the feeding factor (FF) from Equation (2) for the highest possible result $(E R=6)$, applying the values in Table 3 for each case. The prediction vectors and forecast values were the FF obtained with Vensim modeling, and the falconer trial-and-error output labelled "Actual Observed" and "M/F Model" was the FF from Equation (2) for the highest possible result $(E R=6)$, applying values in Table 4 for each case.

\section{Results and Discussion}

\subsection{Simulation Results and Graphical Information}

Vensim software allows simulation results to be configured in several ways. This can be in tables, diagrams, graphics, or exportable files in .csv or .txt format that may be of interest in order to subsequently perform statistical analysis on the results. Figures 8 and 9 show examples of results that were obtained from the Vensim simulations. Figure 8 represents the energy balance that produces a weight increase or reduction, and Figure 9 represents the forecast vs. actual weight for the time frame selected for a female specimen of Falco rusticolus peregrinus (raptor \#01HPGH).

The feeding factor results, listed in a table format, provide the numerical information that the falconer can use to determine an initial feeding baseline in order to keep the raptor feeding between the first and third percentile limits; these limits may lead to the best results when the raptor is released. As for the weight forecast, Figure 9 shows how Vensim modeling offers a smooth forecast of the raptor's weight. This could be used by airport falconers as a baseline to set new feeding objectives from one year to the next. However, forecasting weight is a difficult research problem because all the nutritional components should be analyzed in order to accept forecast values. Thus, the feeding factor was used as a control parameter to set new feeding objectives, because it refers to a basal metabolic rate that depends on the actual weight of the raptor. 


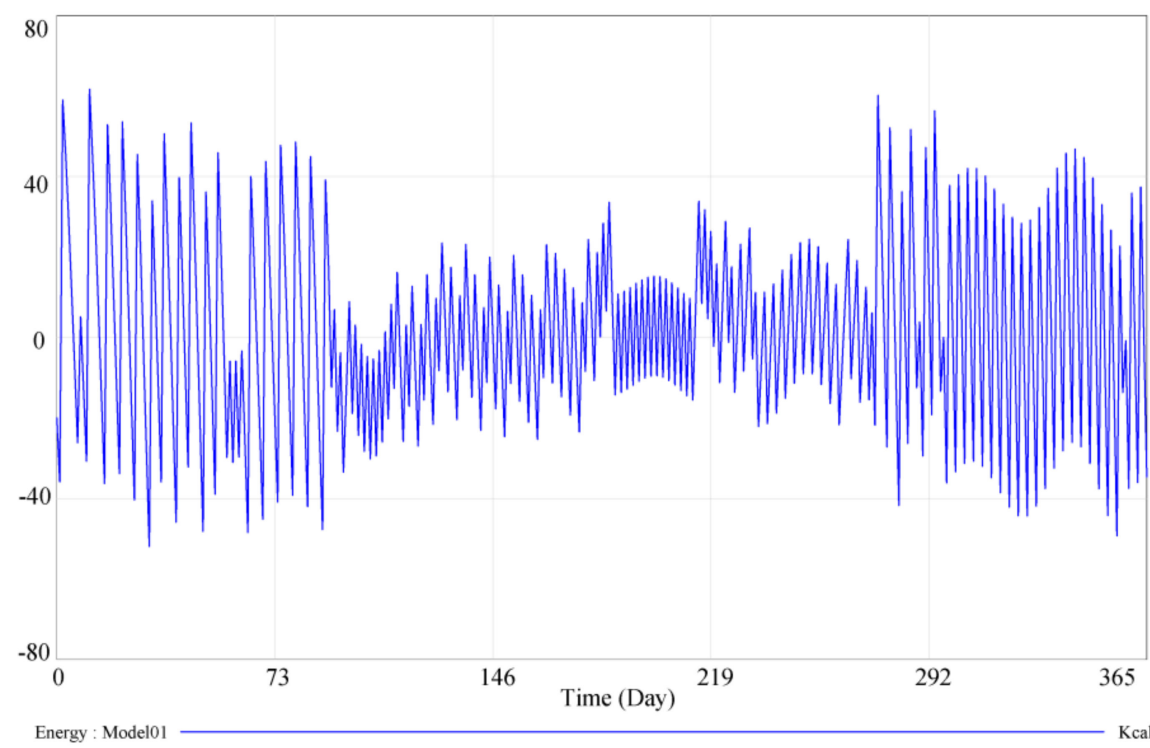

Figure 8. Example of energy balance forecast result for model 01, raptor \#01HPGH.

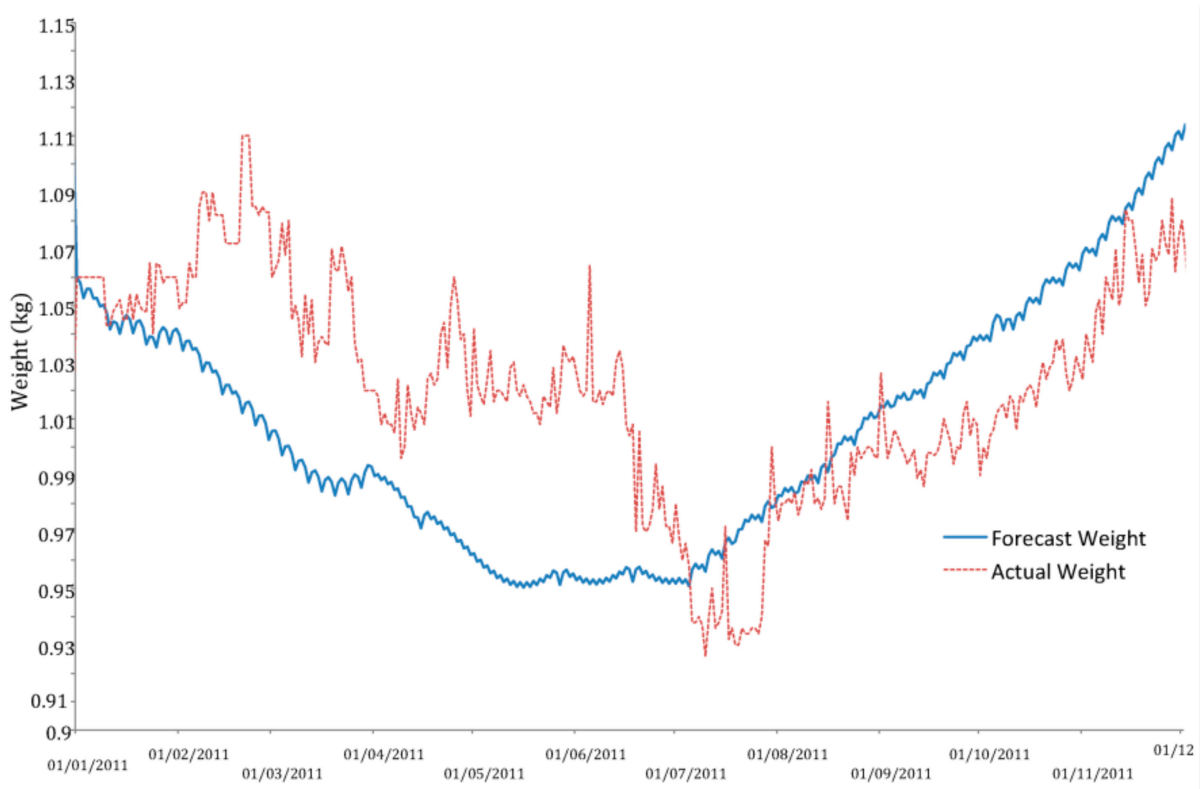

Figure 9. Weight forecast vs. actual weight for model 01, raptor \#01HPGH, applied to 2011.

Therefore, the feeding factor allows the use of a dependent reference variable that can be easily adjusted by airport falconers by applying their own conversion tables of food into calories instead of using the list in Table 5.

The feeding forecast is a dynamic system where the first and third percentile limits provide a range of values in which the feeding should be set by the falconer as a goal. It is difficult to achieve the exact value of the feeding factor because food is supplied in full or partial portions of standard items. This aspect is introduced into the simulation by defining the most common responses of falconers (Table 6) to a diet variation when the feeding factor is over the third percentile (Q3), between the third and first percentiles (inside the Q3-Q1 interval), or below the first percentile (Q1).

This circumstance explains why the feeding factor variance increases when its limits (Q3-Q1) are considerably close in value (Figures 10 and 11). As for the reliability of simulations, results were compared with the actual information recorded by the falconer from 2004 to 2014 . This made it possible to determine the mean squares and symmetric mean absolute percentage errors by analyzing 
the differences between the forecast feeding factor and the feeding factor that can lead to the best results for each raptor when released, referring to the third percentile.

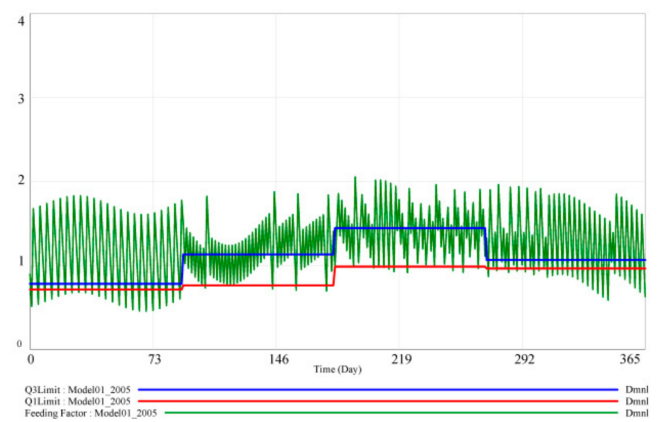

(a)

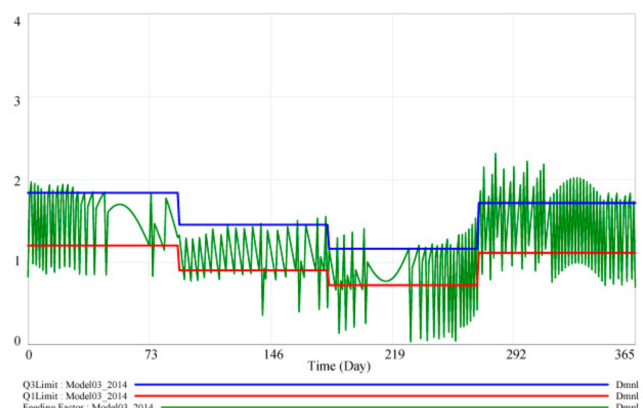

(c)

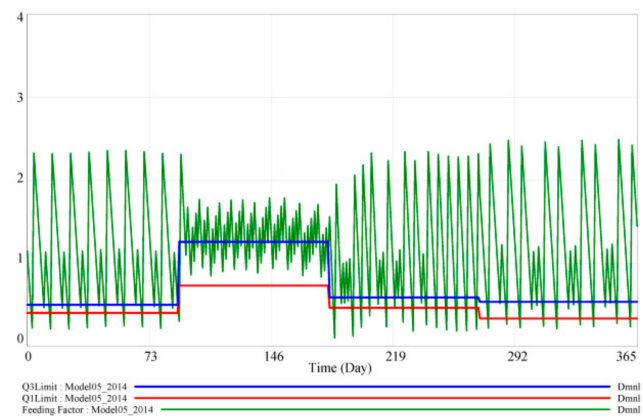

$(\mathbf{e})$

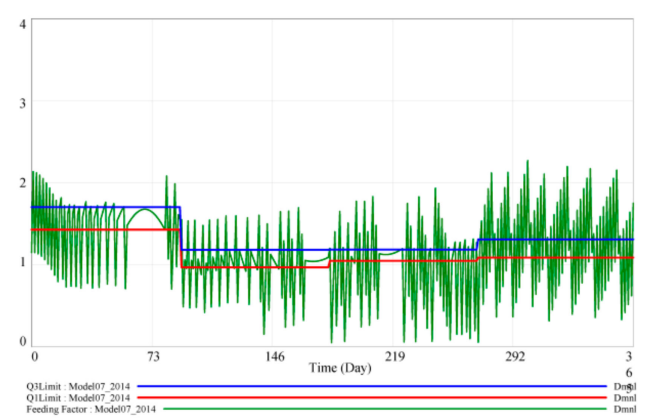

$(\mathrm{g})$

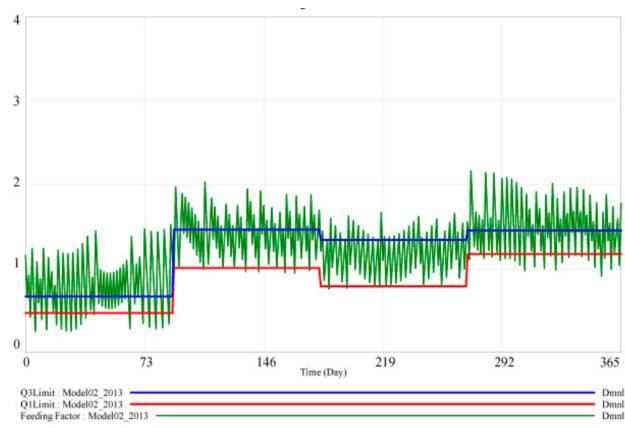

(b)

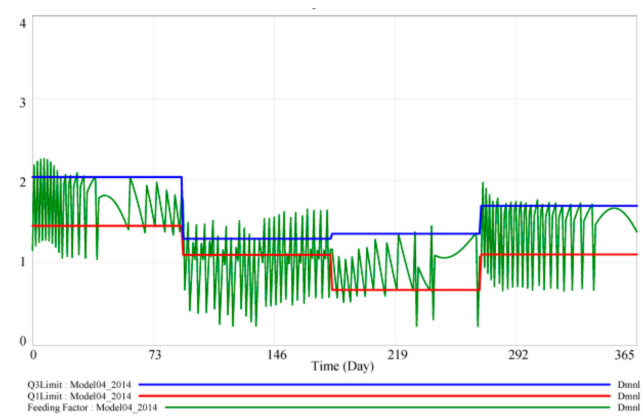

(d)

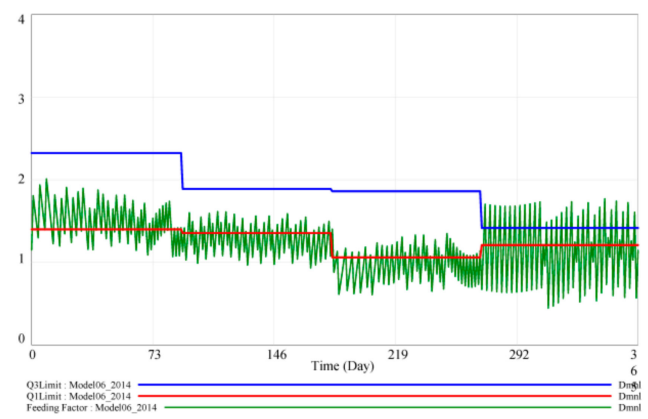

$(\mathbf{f})$

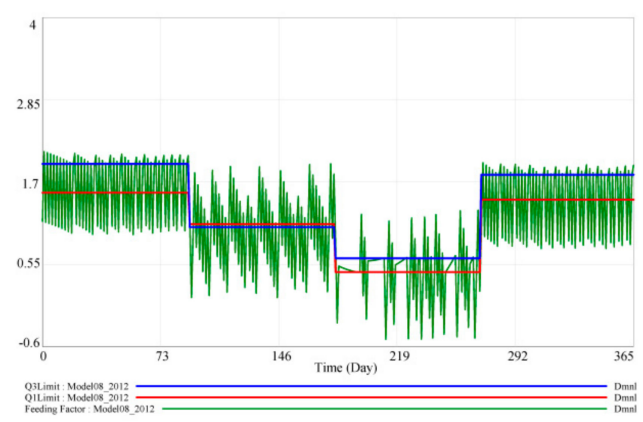

(h)

Figure 10. Feeding factor plots for models 01-08: (a) raptor \#01HPGH; (b) raptor \#02HSGH; (c) raptor \#03HPGM; (d) raptor \#04HPGM; (e) raptor \#05HPH; (f) raptor \#06HPGM; (g) raptor \#07HPGM; (h) raptor \#08HGSM. 


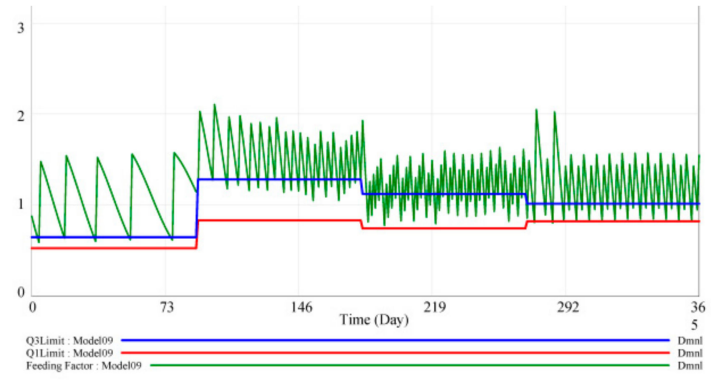

(a)

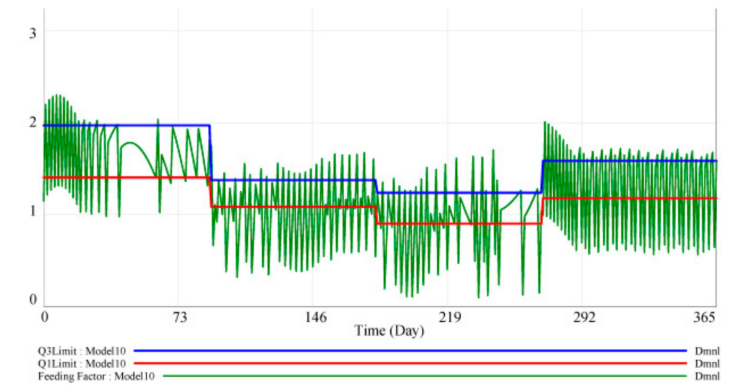

(b)

Figure 11. Feeding factor plot according to raptor gender: (a) female and (b) male.

\subsection{Simulation Reliability Results}

The mean square error is a statistical indicator that penalizes higher differences between forecast and actual values. The symmetric mean absolute percentage error is a statistical indicator that can be used to contrast forecast models even though it is not a fully symmetric method, because the upper and lower values in the forecast are not treated equally. Rather than characterizing the Vensim model error, these indicators were used to identify the model that would fit better as a forecast model of the raptor's feeding process; therefore, the error value must be understood as a relative value used to compare models for a specific raptor and a generic model based on the raptor's gender. The results are summarized in Table 8. The mean square error (MSE) for the models designed with Vensim for each raptor was always lower than that obtained from actual observations of the airport falconer. Thus, it could be assumed that the Vensim model for each raptor can improve the falconer's decision-making process regarding the feeding factor.

Table 8. Results of mean squared error (MSE) and symmetric mean absolute percentage error (SMAPE).

\begin{tabular}{cccccccccc}
\hline $\begin{array}{c}\text { Model } \\
\text { (i) }\end{array}$ & \multicolumn{2}{c}{ MSE } & * (Referring to Q3) & \multicolumn{2}{c}{ SMAPE * } & (Referring to Q3) & \multicolumn{3}{c}{ SMAPE * (Referring to Q3) } \\
\cline { 2 - 9 } & A & B & C & A & B & C & A & B & C \\
\hline 01 & 0.1719 & 0.4812 & 0.1986 & $28.37 \%$ & $46.36 \%$ & $29.09 \%$ & $31.82 \%$ & $49.65 \%$ & $32.12 \%$ \\
02 & 0.1093 & 0.4187 & 0.1301 & $24.68 \%$ & $45.23 \%$ & $28.61 \%$ & $27.58 \%$ & $52.90 \%$ & $30.82 \%$ \\
03 & 0.2570 & 0.2969 & 0.2848 & $34.16 \%$ & $37.44 \%$ & $35.70 \%$ & $48.86 \%$ & $53.95 \%$ & $51.28 \%$ \\
04 & 0.2519 & 0.3120 & 0.3050 & $32.62 \%$ & $35.22 \%$ & $33.72 \%$ & $44.73 \%$ & $47.96 \%$ & $46.11 \%$ \\
05 & 0.6594 & 0.7110 & 0.5506 & $57.84 \%$ & $66.39 \%$ & $61.26 \%$ & $66.34 \%$ & $70.48 \%$ & $63.90 \%$ \\
06 & 0.5516 & 0.7076 & 0.6688 & $46.21 \%$ & $52.91 \%$ & $51.38 \%$ & $54.29 \%$ & $67.96 \%$ & $63.72 \%$ \\
07 & 0.2670 & 1.2907 & 0.2981 & $38.29 \%$ & $53.93 \%$ & $46.68 \%$ & $50.31 \%$ & $62.05 \%$ & $55.48 \%$ \\
08 & 0.2595 & 0.5807 & 0.2777 & $35.86 \%$ & $42.85 \%$ & $37.74 \%$ & $38.90 \%$ & $49.29 \%$ & $47.58 \%$ \\
\hline
\end{tabular}

A: Forecast vector was FF values obtained with Vensim model. B: Forecast vector was formed by FF values recorded by falconer using a trial-and-error system. C: Forecast vector was set with FF values from Equation (2) for ER = 6 applying values from Table 4 in each case. Reference vector corresponded to FF from Equation (2) for ER $=6$ applying values from Table 3 in each case. * Includes all data; ** excludes data inside interval [Q1,Q3].

The generic model that depends on the raptor's gender also provided a lower MSE than actual observations, which can be used for new case studies that do not have sufficient data to design a specific model. The models, except model 05, yielded a lower MSE compared to a reference generic model. The MSE of the generic and specific models was 0.5506 and 0.6594 , respectively. The reason for this was that model 05 represented a young raptor that was in a growing trend instead of a conventional activity. This motivated the falconer to increase the raptor's weight with increased feeding, which resulted in a bigger input of calories into the Vensim model beyond the required input (Table 7).

Although error comparison is a valid method to set acceptance criteria to determine which model fits better with actual values referred to in the Q3 limit (previously calculated), there could be several forecast values noted as errors, even though these may be within the acceptance interval [Q1,Q3]. 
Therefore, to determine the symmetric mean absolute percentage error (SMAPE), two sets of values were calculated: SMAPE values of all databases that conformed with all forecast values, and SMAPE values of forecast databases in which feeding factors within the interval [Q1,Q3] were removed.

Table 8 summarizes SMAPE * results, which correspond with the symmetric mean absolute percentage error calculated by considering the value of the third percentile of the feeding factor that yielded the best result for the raptor's release. The list also includes SMAPE **, which corresponds with the symmetric mean absolute percentage error calculated only for feeding forecast values outside the interval [Q1,Q3]. It can be observed that the lowest value of SMAPE * was $24.68 \%$, corresponding to model 02, which was designed for a female specimen of Falco cherrug rusticolus. The highest value was $57.84 \%$, corresponding to model 05 , which was designed for a female specimen of Falco peregrinus. The same trend is observed for SMAPE ${ }^{* *}$, with values of 27.58 and $66.04 \%$ for models 02 and 05 , respectively.

These results reveal that in all cases, specific models had lower error percentages than the falconer's actual observations. This further confirms that the Vensim model can be used to define a feeding factor baseline to lead raptors to the right-hunger point. Moreover, this shows that generic models that depend on raptor gender are suitable for forecasting when records are not sufficient to perform statistical studies to design specific models.

\section{Conclusions and Future Research}

The aim of this research was to provide a baseline for the raptor feeding factor for airport falconry in order to aid falconers in the decision-making process to lead raptors to the right-hunger point and keep them there. A dynamic system was designed based on an analogy with the water tank filling problem, where several feedback inputs allow control of feeding the raptor according to an interval defined by the first and third percentile of the feeding factor, which would lead the raptor to succeed when released.

The simulations performed allowed this baseline to be defined in a one-year framework, which could be easily updated to obtain new forecast values of the feeding factor. To this end, Vensim software, with its user-friendly interface, proved to be a useful tool to set all required parameters in the analysis. However, several raptor species could not be simulated because certain features of the case study did not include all types of raptors that can be used in airport falconry.

Even though this research did not analyze other case studies, it opens new research lines where these results may be considered in relation to other airport features that may affect the feeding process; consequently, adjustments to improve the results may be proposed. This perspective is deemed relevant, because in the early stage of this research, a strategic communication model was proposed to allow knowledge transfer among airport falconers through record sharing (Figure 12).

The developed Vensim model can be freely shared with other airport falconers as a key to unlock the transfer of knowledge acquired from this study. Accordingly, a new study that includes new parameters, such as the wildlife impact ratio per 100,000 operations (as defined by the International Civil Aviation Organization), could be initiated [32]. This could encourage airport stakeholders to analyze other case studies where the information obtained from this study could be used to investigate new ways of evaluating the efficiency of airport falconry activities following a risk property-based classification and big data analysis [33] alongside new ways of pattern recognition within big data processes [34]. In addition, incoming research lines with regard to finding the right-hunger point in addition to the best expected behavior of raptors when they are released can take advantage of new solutions for the decision problem using fuzzy problem solving, such as by fuzzy Laplace transforms [35], which could extend the research scope of this paper.

Furthermore, the feeding factor forecast opens a new cross-research opportunity by considering logistical studies regarding food acquisition for raptors and the use of traceable food supplier data, which could help airport falconers to optimize the food request process by minimizing delivery time and transport cost. 


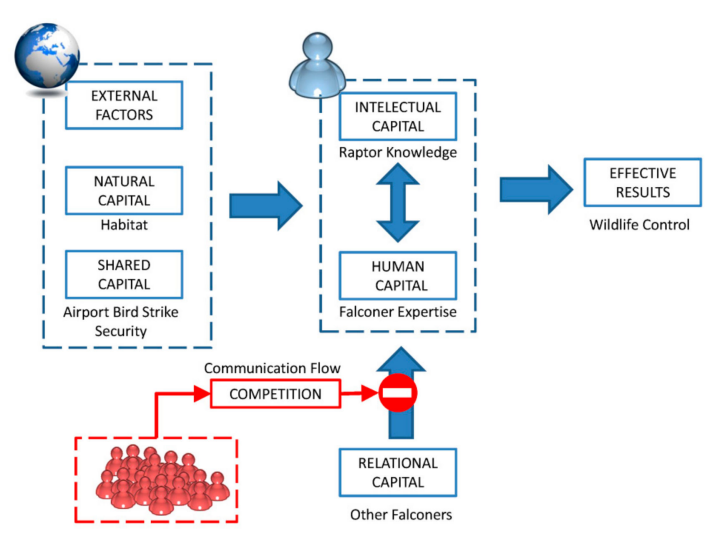

(a)

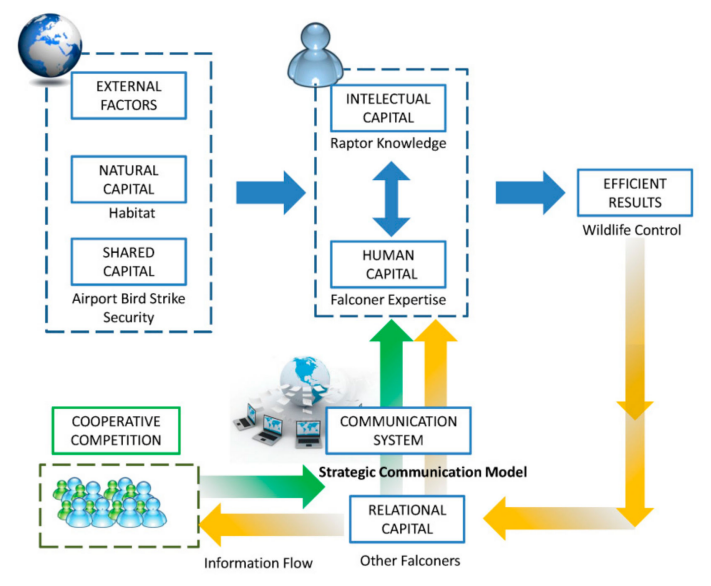

(b)

Figure 12. Comparison between (a) actual and (b) proposed system design for airport falconry.

Author Contributions: Conceptualization, J.L.R.-G.; methodology, J.L.R.-G. and F.C.-B.; software, F.C.-B.; validation, J.L.R.-G. and A.J.B.P.; formal analysis, A.J.B.P.; investigation, J.L.R.-G. and A.J.B.P.; resources, J.L.R.-G. and A.J.B.P.; data curation, J.L.R.-G. and F.C.-B.; writing-original draft preparation, J.L.R.-G.; writing-review and editing, A.J.B.P. and F.C.-B.; supervision, J.L.R.-G. All authors have read and agreed to the published version of the manuscript.

Funding: This research received no external funding.

Acknowledgments: The authors would like to express their sincere gratitude to Desheng Wu from the University of the Chinese Academy of Sciences and Stockholm University, whose comments helped to improve this paper considerably.

Conflicts of Interest: The authors declare no conflict of interest.

\section{References}

1. Dolbeer, R.A.; Wright, S.E.; Weller, J.; Begier, M.J. Wildlife Strikes to Civil Aircraft in the United States, 1990-2014. no. Serial Report Number 15, 2014. Available online: https://rosap.ntl.bts.gov/view/dot/6461 (accessed on 4 December 2016).

2. Allan, J.R. The cost of bird strikes and birdstrike prevention. In Human Conflicts with Wildlife: Economic Considerations; National Wildlife Research Cener: Fort Collins, CO, USA, 2000; Volume 1, pp. 147-153. Available online: https://digitalcommons.unl.edu/nwrchumanconflicts/18 (accessed on 12 March 2014).

3. Anderson, A.; Carpenter, D.S.; Begier, M.J.; Blackwell, B.F.; DeVault, T.L.; Shwiff, S.A. Modeling the cost of bird strikes to US civil aircraft. Transp. Res. Part Transp. Environ. 2015, 38, 49-58. [CrossRef]

4. Schwarz, K.B.; Belant, J.L.; Martin, J.A.; DeVault, T.L.; Wang, G. Behavioral traits and airport type affect mammal incidents with U.S. civil aircraft. Environ. Manag. 2014, 54, 908-918. [CrossRef]

5. Hesse, G.; Rea, R.V.; Booth, A.L. Wildlife management practices at western Canadian airports. J. Air Transp. Manag. 2010, 16, 185-190. [CrossRef]

6. Blackwell, B.; DeVault, T.; Fernández-Juricic, E.; Dolbeer, R. Wildlife collisions with aircraft: A missing component of land-use planning for airports. Landsc. Urban Plan. 2009, 93, 1-9. [CrossRef]

7. Zugasti, M. Birds at Airports: The Use of Falconry, 4th ed.; Aena Aeropuertos, S.A.: Madrid, Spain, 2008; ISBN 9788496456884.

8. Cook, A.; Rushton, S.; Allan, J.; Baxter, A. An Evaluation of Techniques to Control Problem Bird Species on Landfill Sites. Environ. Manag. 2008, 41, 834-843. [CrossRef] [PubMed]

9. Yang, D.-D.; Zhang, Z.-Q.; Hu, M.-W. Ranking birdstrike risk: A case study at Huanghua International Airport, Changsha, China. Acta Ecol. Sin. 2010, 30, 85-92. [CrossRef]

10. Kitowski, I.; Grzywaczewski, G.; Cwiklak, J.; Grzegorzewski, M.; Krop, S. Falconer activities as a bird dispersal tool at Deblin Airfield (E Poland). Transp. Res. Part Transp. Environ. 2011, 16, 82-86. [CrossRef] 
11. Blackwell, B.F.; Seamans, T.W.; Schmidt, P.M.; Vault, T.L.D.; Belant, J.L.; Whittingham, M.J.; Martin, J.A.; Fernández-Juricic, E. A framework for managing airport grasslands and birds amidst conflicting priorities. Ibis 2013, 155, 199-203. [CrossRef]

12. Ning, H.; Chen, W. Bird strike risk evaluation at airports. Aircr. Eng. Aerosp. Technol. Int. J. 2014, 86, $129-137$. [CrossRef]

13. Matyjasiak, P. Methods of bird control at airports. In Theoretical and Applied Aspects of Modern Ecology; Wydawnictwo Uniwersytetu Kardynala Stefana Wyszynskiego: Warsaw, Poland, 2008; Volume 1, pp. 171-203. ISBN 978-83-7072-562-4.

14. Roca-González, J.L.; Vera López, J.A.; Fernández Martínez, M. Raptor's “Right Hunger" Characterization to Develop Sustainable Exclusion Areas for wildlife at Civil \& Military Airports. Appl. Math. Nonlinear Sci. 2016, 1, 335-344. [CrossRef]

15. Staton, D. An Analysis of Australian Birdstrike Occurrences 2002 to 2006; Safety publications, Australian Transport Safety Bureau: Camberra City, Australia, 2008; p. 139. Available online: https://www.atsb.gov.au/ publications/2008/ar2008027/ (accessed on 27 February 2020).

16. Thiériot, E.; Patenaude-Monette, M.; Molina, P.; Giroux, J.-F. The Efficiency of an Integrated Program Using Falconry to Deter Gulls from Landfills. Animals 2015, 5, 214-225. [CrossRef] [PubMed]

17. Littauer, G.; Glahn, J.; Reinhold, D.; Brunson, M.; Brunson, M.; Brunson, M. Control of Bird Predation at Aquaculture Facilities: Strategies and Cost Estimates; SRAC Publication, Southern Regional Aquaculture Center: Stoneville, MS, USA, 1997.

18. Clark, L.; Shivik, J.A.; Watkins, R.A.; VerCauteren, K.T.; Yoder, J.K. Human Conflicts with Wildlife: Economic Considerations. In Proceedings of the National Wildlife Research Center Symposium, Fort Collins, CO, USA, 1-3 August 2000; Available online: https:/digitalcommons.unl.edu/nwrchumanconflicts/ (accessed on 27 February 2020).

19. Wilke, S.; Majumdar, A.; Ochieng, W.Y. A framework for assessing the quality of aviation safety databases. Saf. Sci. 2014, 63, 133-145. [CrossRef]

20. Tvrdon, L.; Fedorko, G. Usage of Dynamic Simulation in Pressing Shop Production System Design. Int. J. Simul. Model. 2020, 19, 185-196. [CrossRef]

21. Roca-Gonzalez, J.-L. Designing dynamical systems for security and defence network knowledge management. A case of study: Airport bird control falconers organizations. Discrete Contin. Dyn. Syst.-S 2015, 8, 1311. [CrossRef]

22. International Civil Aviation Organization. Airport Services Manual Part 3 Wildlife Control and Reduction, 4th ed.; International Civil Aviation Organization: Montréal, QC, Canada, 2012; ISBN 978-92-9231-929-8.

23. Burger, J. Bird Control at Airports. Environ. Conserv. 1983, 10, 115-124. [CrossRef]

24. Ceballos, J.; Justribó, J.H. Manual Básico y Ético de Cetrería; Avium: Madrid, Spain, 2011; ISBN 978-84-85707-63-8.

25. Ferguson-Lees, J.; Christie, D.A. Raptors of the World; Houghton Mifflin: Boston, MA, USA, 2001; ISBN 978-0-618-12762-7.

26. Glasier, P. Falconry and Hawking; Charles Branford Publisher: London, UK, 1986; ISBN 978-07-13455557.

27. Sedgwick, C.J.; Haskell, A.; Pokras, M. Scaling drug dosages for animals of diverse body sizes. Wildl. Rehabilators 1986, 5, 3-11.

28. Porkas, M.; Karas, A.; Kirkwood, J.; Sedgwick, C.J. An introduction to allometric scaling and its uses in raptor medicine. In Raptor Biomedicine; University of Minesota Press: Minneapolis, MN, USA, 1993; Volume 37, pp. 211-228.

29. Barton, N.W.H.; Houston, D.C. A comparison of digestive efficiency in birds of prey. Ibis 1993, 135, 363-371. [CrossRef]

30. Morley, S.K.; Brito, T.V.; Welling, D.T. Measures of Model Performance Based On the Log Accuracy Ratio. Space Weather 2018, 16, 69-88. [CrossRef]

31. Kim, S.; Kim, H. A new metric of absolute percentage error for intermittent demand forecasts. Int. J. Forecast. 2016, 32, 669-679. [CrossRef]

32. Roca-González, J.-L.; Vera-Lopez, J.-A.; Rodriguez-Bermudez, G. Organisational and costing aspects to prevent wildlife strikes on airports: A case study of Spanish airport security managers. Saf. Sci. 2020, 122, 104520. [CrossRef] 
33. Wu, D.; Birge, J.R. Risk Intelligence in Big Data Era: A Review and Introduction to Special Issue. IEEE Trans. Cybern. 2016, 46, 1718-1720. [CrossRef]

34. Xie, T.; Liu, R.; Wei, Z. Improvement of the Fast Clustering Algorithm Improved by K-Means in the Big Data. Appl. Math. Nonlinear Sci. 2020, 5, 1-10. [CrossRef]

35. Çitil, H.G. Investigation of A Fuzzy Problem by the Fuzzy Laplace Transform. Appl. Math. Nonlinear Sci. 2019, 4, 407-416. [CrossRef]

Publisher's Note: MDPI stays neutral with regard to jurisdictional claims in published maps and institutional affiliations.

(C) 2020 by the authors. Licensee MDPI, Basel, Switzerland. This article is an open access article distributed under the terms and conditions of the Creative Commons Attribution (CC BY) license (http://creativecommons.org/licenses/by/4.0/). 